\title{
Pharmaceutical crystallization in Couette- Taylor crystallizer: A case study of polymorphism of amino acid L-glutamic acid
}

- Khuu Chau Quang

- Dang Truong Giang

- Trinh Thi Thanh Huyen

- Nguyen Anh Tuan

Institute of Chemical Technology, Vietnam Academy of Science and Technology (VAST)

(Manuscript Received on Octorber $08^{\text {th }}, 2016$, Manuscript Revised Octorber 09 ${ }^{\text {th }}$, 2016)

\begin{abstract}
The influence of intensity Taylor vortex Couette-Taylor (CT) crystallizer was at least 2.0 flow in Couette-Taylor crystallizer on the crystallization of polymorphic amino acid Lglutamic acid was investigated in cooling crystallization. Here, the L-glutamic acid was chosen as the model crystal product, where it has two kinds of polymorphism including the unstable phase $\alpha$-form and stable phase $\beta$-form crystal. In cooling crystallization, the $\alpha$-form crystal transformed to the $\beta$-form crystal corresponding to the phase transformation of $\alpha$ form to $\beta$-form crystal. The present study found that the selective polymorphism of $\alpha$-form and $\beta$ form crystal as well as the phase transformation significantly depended on the intensity of turbulent Taylor vortex flow in Couette-Taylor crystallizer. Here, the selective $\beta$-form nucleation and phase transformation were remarkably promoted as increasing the rotation speed of inner cylinder in Couette-Taylor crystallizer. By comparison with the times more effective as regards the selective $\beta$ form polymorphism and phase transformation time. The advantage of CT crystallizer over the conventional ST crystallizer was explained in terms of the high shear stress and mass transfer of turbulent Taylor vortex flow in CT crystallizer. Here, the shear stress of Taylor vortex flow in CT crystallizer was at least 23.0 times higher than that of fluid motion in conventional ST crystallizer, whereas the mass transfer of Taylor vortex flow in CT crystallizer was at least 1.2 times higher than that of fluid motion in conventional ST crystallizer. As such, the high turbulent shear stress of Taylor vortex flow was expected to promote the $\beta$-form nucleation via the effective molecules alignment, whereas the high mass transfer of Taylor vortex flow facilitated the dissolution rate of $\alpha$-form and growth rate of $\beta$-form crystal, resulting in an acceleration of phase transformation rate.
\end{abstract} conventional stirred tank (ST) crystallizer, the 
Keywords: Crystallization, polymorphism, nucleation, crystal growth, agglomeration/breakage, Couette-Taylor crystallizer.

\section{INTRODUCTION}

Crystallization is a significant separation, purification and particle technology used in various life science industries including pharmaceuticals, foods and fine chemicals, etc. Crystallization is known as the crucial process in order to obtain high quality of solid products including purity, polymorphism, shape, size and size distribution, etc [1-3].

Even though the crystallization has a long history, it has not been well understood because the different material has different fundamental crystallization phenomenon including nucleation, crystal growth, agglomeration/ breakage, polymorphism, etc. In crystallization, polymorphism is a very interesting phenomenon, where the solid product can exist in more than one crystal structure because of a varied conformation and arrangement of molecules in a crystal lattice. Polymorphism is very common phenomenon especially for the organic compounds, where at least $50 \%$ of organic drug has polymorphism. Since the different crystal structure has a different physical-chemical property including bioactivity, stability, solubility, hardness, etc, controlling polymorphism become a vital issue in any pharmaceutical crystallization process [46].

Since the conformation and packing of molecules in solution directly depended on the fluid hydrodynamic in crystallizer, the fluid hydrodynamic is certainly considered as the key factor to control the selective and phase transformation of polymorphism [7-9]. For example, Sypek et al [7] reported that the stable phase of carbamazepine was selectively obtained in stirred crystallization, whereas the unstable phase was preferably crystallized in a stagnant crystallization. As regards the phase transformation, Davey et al [8] indicated that the completed phase transformation of 2,6dihydroxybenzoic acid from unstable to stable phase required at least 20 days in a stagnant crystallization, but it was significantly reduced to only 2-3 days in stirred crystallization. A similar phenomenon was observed in case of taltireline crystallization, where the agitation speed was attributed to promote the phase transformation of unstable phase to stable phase [9], etc.

Our patent Couette-Taylor crystallizer is known as the unique crystallizer which has an effective fluid hydrodynamic that is called the Taylor vortex flow. Couette-Taylor crystallizer has been widely applied in various crystallization processes including batch and continuous system for many organic and inorganic compounds. In addition, the flexibility of Couette-Taylor crystallizer is also demonstrated when it can be applied for varied crystallization techniques including the reaction, anti-solvent and cooling crystallization, etc [1016]. In the polymorphic organic and inorganic material crystallization, the Couette-Taylor crystallizer has been already applied in order to control the selection and phase transformation of polymorphic crystal. For instance, Nguyen et al [10-15] indicated that the phase transformation of guanosine 5-monophosphate from amorphous phase to crystalline hydrate phase was significantly facilitated over 5.0 times as using the Couette-Taylor crystallizer compared to that 
in the conventional stirred tank crystallizer. Moreover, Lee et al [16] reported that the stable phase of sulfamerazine crystal was more favorably performed as using the CouetteTaylor crystallizer compared to that in the conventional stirred tank crystallizer, etc.

Amino acids are valuable materials which have a wide application in various products including pharmaceutical, food, fine chemical, agricultural, cosmetic, etc. Almost amino acid crystal products have polymorphism such as Lglutamic acid, L-histidine, Glycine, L-lysine, etc. In our current work, the amino acid Lglutamic was chosen as a model crystal product to demonstrate the effectiveness of CouetteTaylor crystallizer in controlling polymorphism of amino acid. It is well known that L-glutamic acid crystal has two kinds of polymorphic crystal including the unstable phase $\alpha$-form and stable phase $\beta$-form crystal, in which the unstable phase $\alpha$-form transformed into the stable phase $\beta$-form crystal during crystallization. In case of L-glutamic acid crystallization, Kitamura et al [17] reported that the selective polymorphism of unstable phase $\alpha$ form was successfully obtained when the solution was agitated, whereas a polymorphic mixture of $\alpha$-form and $\beta$-form crystal was crystallized in the stagnant solution. Florence et al [18] also indicated that the selective polymorphism of stable phase $\beta$-form crystal was performed as using the oscillatory baffled crystallizer, etc.

Although the crystallization of amino acid L-glutamic acid has been carried out, most of them were conducted in the conventional stirred tank crystallizer, where the phase transformation of unstable phase $\alpha$-form to stable phase $\beta$-form required an extreme long crystallization time even beyond 40 hours. Meanwhile, the encrustation or blockage often occurs as using the other crystallizer such as oscillatory baffled and plug flow crystallizer, etc. Therefore, it is really necessary to develop the more effective crystallizer in order to control the polymorphism of amino acid L-glutamic acid in crystallization. In contrast to previous studies, the CouetteTaylor crystallizer in our current work was developed to facilitate the polymorphic crystallization of L-glutamic acid, where the dependency of selective polymorph and phase transformation on the intensity Taylor vortex flow in Couette-Taylor crystallizer was deeply investigated. Moreover, according to Biradha et al [19-20], the crystallization research is not found in the South and East Asian countries including Vietnam, Indonesia, Philippine, Malaysia, etc, meaning that the crystallization research should be developed in the South and East Asian countries.

\section{EXPERIMENTAL}

The Couette-Taylor crystallizer (CT) made of stainless steel was designed according to Nguyen et al [10-15]. By comparison, the conventional stirred tank (ST) crystallizer was designed following the standard Rushton tank crystallizer [10-15], which was made of stainless steel and installed with turbineimpeller and four baffles for effective mixing. Here, the CT and ST crystallizer with $400 \mathrm{ml}$ working volume were operated under the same crystallization conditions. During cooling crystallization, the temperature of both crystallizers was controlled via the circulating coolant from the chiller, while the rotation speed of inner cylinder in CT crystallizer and the agitation speed of impeller in ST crystallizer were controlled via the DC motor. 
Amino acid L-glutamic acid material ( $\geq 98 \%$ purity) was purchased from Sigma Aldrich Company. The feed solution was prepared by dissolving the material into the distilled water at $70^{\circ} \mathrm{C}$, and the concentration was always fixed at $45(\mathrm{~g} / \mathrm{L})$. The CT and ST crystallizer were initially filled with the feed solution, and then operated as the batch mode cooling crystallization with cooling rate of $0.5\left({ }^{0} \mathrm{C} / \mathrm{min}\right)$. The products were periodically taken from the crystallizers and quickly filtered by using a vacuum pump. The crystal samples were then dried in a desiccator to analyze the shape, size, size distribution, polymorphism, etc. Here, the shape and structure of crystal product were monitored and confirmed by Video microscope and XRD patterns (M18XHF-SRA, Japan), respectively, while the crystal fraction of $\beta$-form was detected by the FT-IR spectroscopy [21]. During cooling crystallization, the solution temperature was continuously monitored by using the temperature indicator (Korea).

\section{RESULTS AND DISCUSSION}

\subsection{Characteristic of Taylor vortex flow in Couette-Taylor crystallizer}

As mentioned in above section, the fluid hydrodynamic in crystallizer is a key factor to determine the selection and phase transformation of polymorphism. Therefore, the fluid hydrodynamic of Couette-Taylor crystallizer should be clearly understood before investigating the crystallization. In CouetteTaylor crystallizer, when the inner cylinder is rotated, the centrifugal force of inner cylinder make the fluid element move from the surface of inner cylinder to the surface of outer cylinder
[10-15]. At a certain rotating speed, when the centrifugal force is larger than the viscous force, the fluid hydrodynamic in the gap cylinders between the inner and outer cylinder becomes instability. The ratio of centrifugal force to viscous force is expressed via the dimensionless Taylor number (Ta), and based on the Taylor number the fluid hydrodynamic regime of Couette-Taylor crystallizer can be the laminar Couette flow, laminar Taylor vortex flow, singly wavy vortex flow, doubly wavy vortex flow, weakly turbulent wavy vortex flow and turbulent vortex flow. As such, the Taylor vortex flow in Couette-Taylor crystallizer appears when the Taylor number (Ta) is beyond the critical value that denoted the critical Taylor number $\left(\mathrm{Ta}_{\mathrm{c}}\right)$. It is well known that the Taylor vortex flow is the strong periodic circular fluid motion which has the high mass/heat transfer and homogeneous mixing condition. Since the one pair of Taylor vortex flow is assumed as a micro-stirred tank crystallizer, the CouetteTaylor crystallizer can be considered as a series of connected micro-stirred tank crystallizer, as shown in Figure 1. Thus, it is expected that the Couette-Taylor crystallizer will be more effective than the stirred tank crystallizer as regards the amino acid L-glutamic acid crystallization. In present study, the fluid hydrodynamic in Couette-Taylor crystallizer was designed as the Taylor vortex flow in a whole range of operating conditions, implying that the crystallization of amino acid L-glutamic acid in Couette-Taylor crystallizer is always conducted under the Taylor vortex flow, as displayed in Figure 1.

\section{Trang 14}




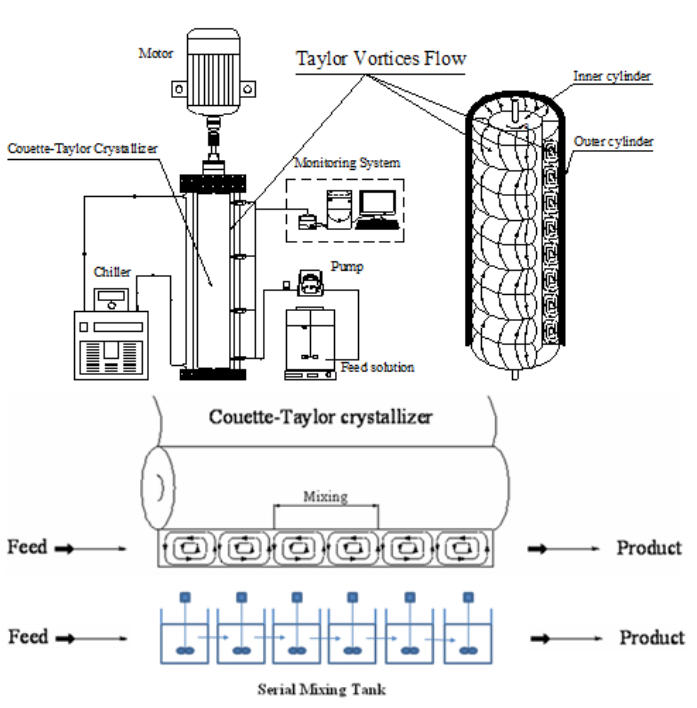

Figure 1. Experimental system and schematic of Taylor vortex flow in Couette-Taylor crystallizer

3.2. Polymorphic crystallization of $\mathbf{L}$ glutamic acid in Couette-Taylor crystallizer
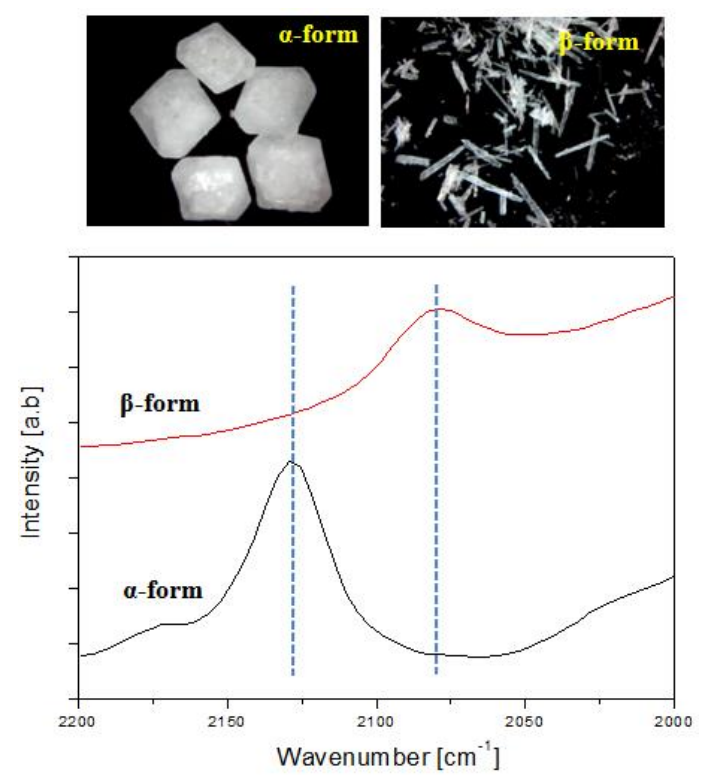

Figure 2. Shape and structure of $\alpha$-form and $\beta$-form crystal

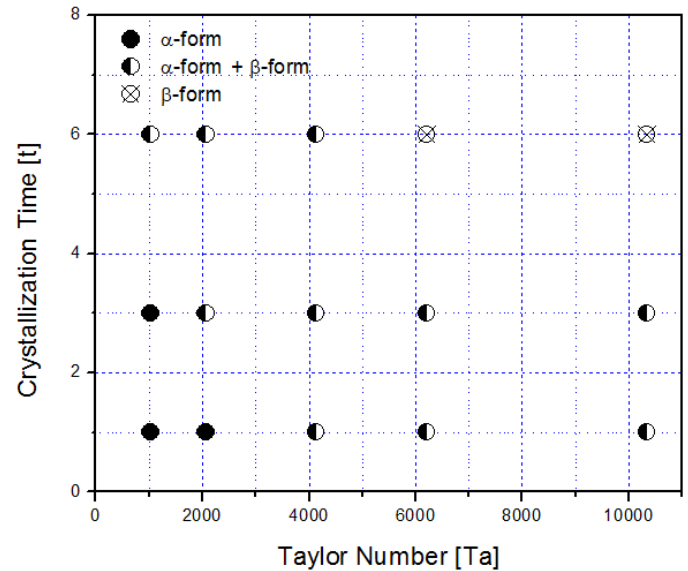

Figure 3. Polymorphism map as regards the effect of intensity Taylor vortex flow and crystallization time in CT crystallizer

In cooling crystallization of L-glutamic acid, the solid product might exist in one of two crystal structures that were known as the unstable phase $\alpha$-form and stale phase $\beta$-form crystal. As shown in Figure 2, the shape of $\alpha$ form crystal was obviously different from the shape of $\beta$-form crystal, in which the shape of $\alpha$ form and $\beta$-form were prism and needle, respectively. Moreover, due to the difference of conformation and packing molecules in crystal lattice, the difference of crystal structure of two polymorphs could be confirmed via the FT-IR spectroscopy, where the spectroscopy showed a difference in characteristic peak between $\alpha$-form and $\beta$-form crystal. Here, the characteristic peak of the $\alpha$-form crystal was $2129 \mathrm{~cm}^{-1}$, while it was $2080 \mathrm{~cm}^{-1}$ in case of $\beta$-form crystal, as shown in Figure 2, meaning that $\alpha$-form and $\beta$ form crystal have distinguished crystal structure and physical-chemical properties. As such, the solid product of L-glutamic acid including pure $\alpha$-form, pure $\beta$-form and mixture of $\alpha$-form and $\beta$-form could be defined as using the FT-IR spectroscopy [21]. 
In general, the $\alpha$-form crystal was crystallized in cooling crystallization and after that it was slowly transformed into the $\beta$-form crystal via the solvent-mediated phase transformation mechanism. Here, the $\alpha$-form crystal initially dissolved into the solution to generate the supersaturation for the nucleation of $\beta$-form crystal that was then epitaxially grown on the surfaces of $\alpha$-form crystal. The phase transformation of $\alpha$-form to $\beta$-form crystal completed after all the $\alpha$-form crystal had dissolved and the $\beta$-form crystal suspended in the equilibrium solute concentration of $\beta$-form solubility. As regards the $\beta$-form crystal products, the completed phase transformation might take a long crystallization time even beyond a week. As such, it was revealed that the fluid hydrodynamic in crystallizer played a key role since it directly impacted on the dissolution of $\alpha$-form crystal, nucleation and growth of $\beta$ form crystal.

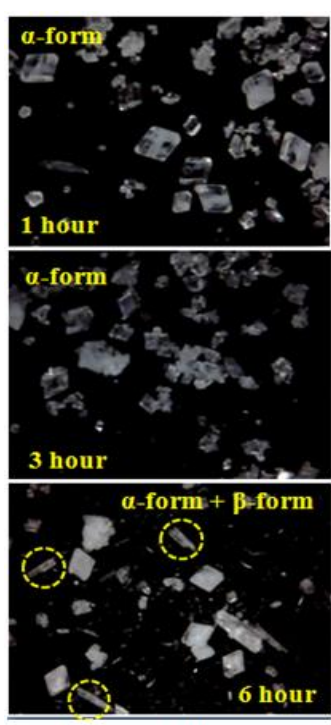

(a)

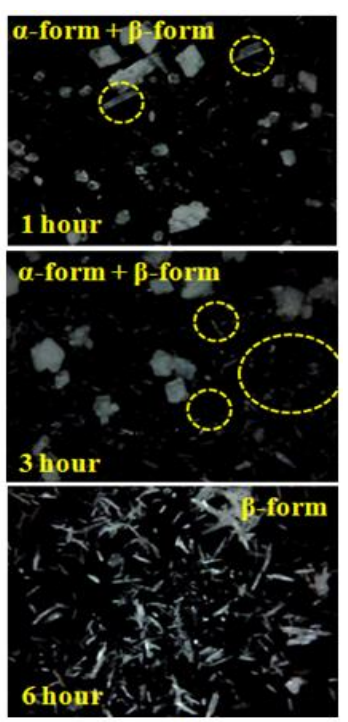

(b)
Figure 4. Typical solid product as regards to the effect of intensity Taylor vortex flow and crystallization time: (a) $\mathrm{Ta}=1034$ and (b) $\mathrm{Ta}=10335$
The influence of intensity Taylor vortex flow in CT crystallizer and crystallization time on the polymorphism of L-glutamic acid was investigated, as shown in Figure 3. When the crystallization was operated at concentration of $45(\mathrm{~g} / \mathrm{L})$ and cooling rate of $0.5\left({ }^{\circ} \mathrm{C} / \mathrm{min}\right)$, the pure $\alpha$-form crystal products were obtained at low intensity fluid hydrodynamic $(\mathrm{Ta}<3000)$ and short crystallization time $(\mathrm{t}<4$ hours). However, the mixture of $\alpha$-form and $\beta$-form crystal product was achieved at a wide range of intensity fluid hydrodynamic and crystallization time as $2000<\mathrm{Ta}<10000$ and $1<\mathrm{t}<6$ hours. Meanwhile, the pure $\beta$-form crystal product was obtained when the intensity fluid hydrodynamic and crystallization time were defined as Ta $>6000$ and $t>6$ hours, respectively.

The morphology of L-glutamic acid polymorphism was also monitored, as shown in Figure 4. When the crystallization was carried out at low intensity Taylor vortex flow as $\mathrm{Ta}=1034<3000$, the solid product had only the prism shape in a range of crystallization time as $1<\mathrm{t}<3$ hour corresponding to the pure $\alpha$-form crystal product. Yet, the mixture morphology including prism and needle shape were observed at crystallization time of 6 hour corresponding to the mixture of $\alpha$-form and $\beta$-form crystal product (Figure 4(a)). When increasing the intensity Taylor vortex flow beyond $\mathrm{Ta}=10335$, the solid product had the mixture shape of prism and needle at crystallization time of only 1 hour, indicating the mixture of $\alpha$-form and $\beta$-form crystal product. However, the only needle shape of pure $\beta$-form crystal was observed at crystallization time of only 6 hour, as depicted in Figure 4(b). As such, the microscope observation matched well with the crystal fraction result mentioned in Figure 3.

\section{Trang 16}


In order to clarify the effect of crystallization time and intensity Taylor vortex flow on the polymorphism of L-glutamic acid in cooling crystallization, the data of Figure 3 was re-organized and illustrated in Figure 5. Here, it was revealed that the crystal fraction of $\beta$-form increased as increasing the crystallization time, meaning that the $\beta$-form crystal was favorably performed when the crystallization time was prolonged. However, the crystal fraction of $\beta$ form was always less than $100 \%$ wt in a range of crystallization time as $1<\mathrm{t}<6$ hour when the intensity fluid hydrodynamic was varied as $1034<\mathrm{Ta}<4134$ (Figure 5(a)), implying that the pure $\beta$-form crystal was only obtained at high intensity Taylor vortex flow such as Ta>6000. As regards the effect of intensity Taylor vortex flow, the crystal fraction of $\beta$-form quickly increased as increasing the intensity Taylor vortex flow and approached $100 \% \mathrm{wt}$ at $\mathrm{Ta}=6000$ and crystallization time of 6 hours (Figure 5(b)). As such, the $\beta$-form nucleation and phase transformation of $\alpha$-form to $\beta$-form crystal strongly depended on the fluid hydrodynamic in crystallizer. Since the $300 \mathrm{rpm}$ of inner cylinder in CT crystallizer corresponded to $\mathrm{Ta}=6000$, it was indicated that the pure $\beta$ form crystal could be obtained at a moderate crystallization condition such as rotation speed of $300 \mathrm{rpm}$ and crystallization time of 6 hours.

As described in above section, the intensity fluid hydrodynamic played a key role to impact on the $\beta$-form nucleation and phase transformation of $\alpha$-form to $\beta$-form crystal. Thus, the effect of intensity fluid hydrodynamic on the nucleation and phase transformation should be investigated.

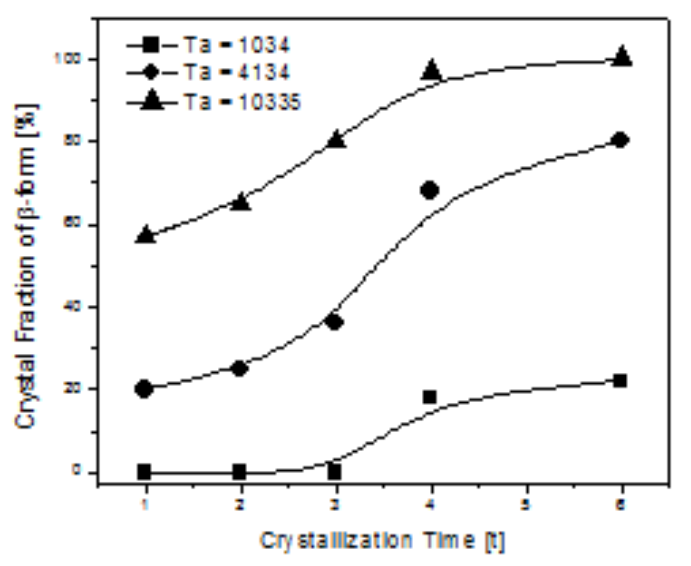

(a)

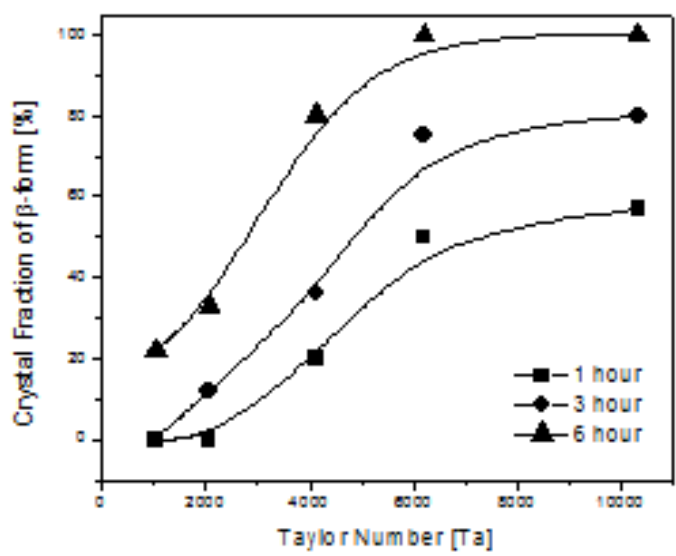

(b)

Figure 5. Effect of crystallization time (a) and intensity Taylor vortex flow (b) on the crystal fraction of $\beta$-form in CT crystallizer

Based on the mechanism of two-step nucleation that was reported by Myerson et al [22], the solute molecules were initially aggregated to form a disorder structure of cluster that had a random arrangement of molecules, but this disorder structure of cluster was then progressively restructured to form an order structure which became a specific polymorphic crystal. As such, the shear stress of fluid hydrodynamic might attribute to the restructure stage to determine the formation of polymorphic crystal, as shown in Figure 6(a). 
Moreover, since the intensity fluid hydrodynamic directly correlated with the mass transfer rate at the solid-liquid interface, the dissolution rate of $\alpha$-form crystal and growth rate of $\beta$-form crystal during the phase transformation certainly depended on the intensity fluid hydrodynamic, as depicted in Figure 6(b)

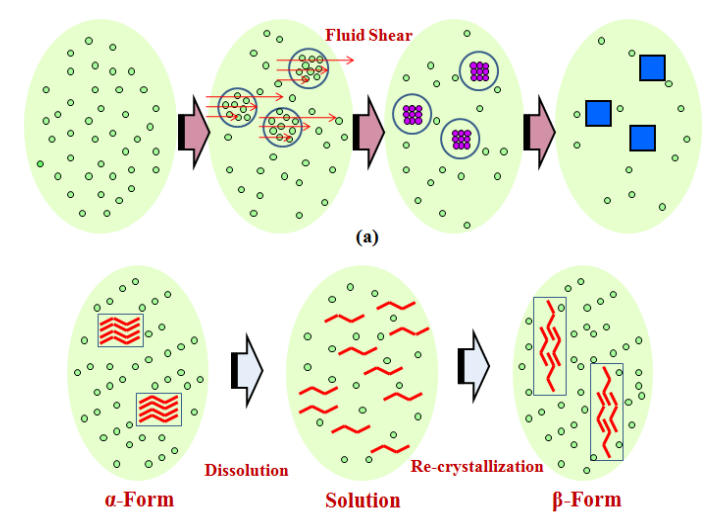

(b)

Figure 6. Schematic influence of fluid shear (a) and mass transfer (b) on the selective polymorphism and phase transformation of L-glutamic acid

For deep understanding, the shear stress and mass transfer of Taylor vortex flow in CT crystallizer were clarified. Here, the shear stress $(\tau)$ of turbulent Taylor vortex flow in CT crystallizer was estimated by Nguyen et al [10$15]$ as

$$
\tau=\frac{T_{M}}{2 \pi r_{i}^{2} L_{C}}=\frac{f \rho_{L} \omega_{i}^{2} r_{i}^{2}}{2}
$$

Where $T_{M}$ is the torque on rotating inner cylinder, defining as $T_{M}=f \pi \rho_{L} \omega_{i}^{2} L_{C} r_{i}^{4}$ and $\mathrm{L}_{\mathrm{C}}$ is the length of inner cylinder. $\omega_{i}$ and $r_{i}$ are angular velocity and radius of inner cylinder, respectively, and $\rho_{L}$ is the density of solution. Plus, the friction factor $f$ is given by an empirical expression as a function of $d / r_{i}$ and the
Reynolds number $\quad(\mathrm{Re}) \quad$ as $f=0.8\left(\frac{d}{r_{i}}\right)^{0.35} \operatorname{Re}^{-0.53}$ for $\operatorname{Re}>\operatorname{Re}_{c} . \quad \operatorname{Re}$ is defined as $\operatorname{Re}=\frac{\omega_{i} r_{i} d}{v}, d$ is the gap between the inner and outer cylinders, and $v$ is the kinematic viscosity of solution. The critical Reynolds number $\operatorname{Re}_{\mathrm{c}}$ has been suggested as $\operatorname{Re}_{c}=41.2\left(\frac{d}{r_{i}}\right)^{-0.5}+27.2\left(\frac{d}{r_{i}}\right)^{0.5}+2.8\left(\frac{d}{r_{i}}\right)^{1.5}$

Meanwhile, the Sherwood number corresponding to the mass transfer at the solidliquid interface in CT crystallizer was expressed by Nguyen et al [10-15] as

$$
S h=2+0.4 T a_{p}^{0.53} S c^{1 / 3}
$$

Where $T a_{p}$ is the Taylor number of particles, defined as $T a_{P}=\left(\frac{\varpi_{i} r_{i} d}{v}\right)\left(\frac{d}{r_{i}}\right)^{1 / 2}$, and the Sherwood number and Schmidt number are defined as $S h=\frac{k d_{p}}{D_{f}}$ and $S_{C}=\frac{v}{D_{f}}$, respectively. Here, $d_{p}$ indicates the diameter of the solid particles, while $D_{f}$ and $k$ are the diffusion coefficient and mass transfer coefficient, respectively.

As such, the shear stress and mass transfer of Taylor vortex flow in CT crystallizer could be estimated via the (1) and (2). As shown in Figure 7 , the shear stress and mass transfer of Taylor vortex flow in CT crystallizer obviously increased as increasing the intensity fluid hydrodynamic, meaning that the higher intensity Taylor vortex flow provided the higher shear stress, so the $\beta$-form nucleation was promoted,

\section{Trang 18}


leading to enhancement of the crystal fraction of $\beta$-form in the solid product (Figure 3-5). Plus, the higher intensity of Taylor vortex flow also provided the higher mass transfer rate, so the dissolution rate of $\alpha$-form and growth rate of $\beta$ form crystal would be more facilitated, implying that the phase transformation of $\alpha$-form to $\beta$ form crystal was more accelerated as increasing the intensity fluid hydrodynamic, which resulted in an increase of the crystal fraction of $\beta$-form in the solid product, as depicted in Figure 3-5.

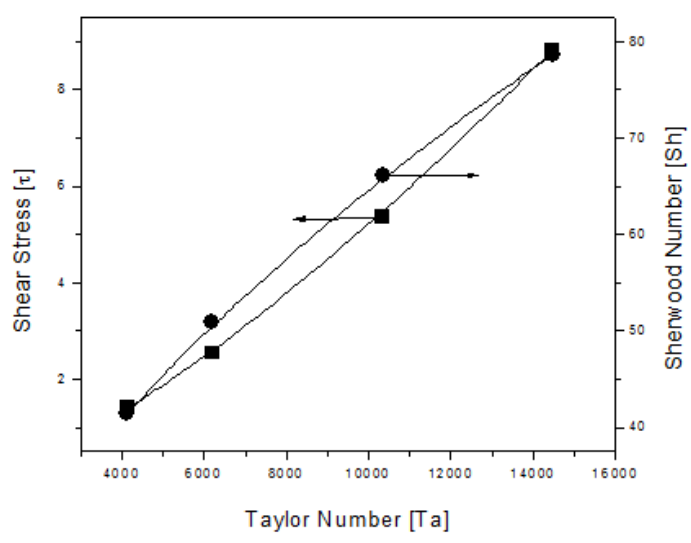

Figure 7. Influence of intensity fluid hydrodynamic on the shear stress and mass transfer in $\mathrm{CT}$ crystallizer

\subsection{Comparison of Couette-Taylor (CT) and Stirred tank (ST) crystallizer}

In order to evaluate the value of CT crystallizer with respect to the polymorphic Lglutamic acid in cooling crystallization, the comparison between the Couette-Taylor (CT) and conventional standard stirred tank (ST) crystallizer was investigated. Since the shear stress and mass transfer of fluid hydrodynamic in crystallizer played key roles to determine the efficiency of L-glutamic acid crystallization, the shear stress and mass transfer of fluid hydrodynamic in both crystallizers should be estimated and compared.
The shear stress of fluid hydrodynamic in conventional ST crystallizer was estimated via the following equation [23]

$$
\tau=\mu \gamma=19 \mu N
$$

Where $\gamma$ and $\mu$ are the shear rate of fluid motion and dynamic viscosity of solution. $\mathrm{N}$ is the rotating speed of the impeller. As using the (1) and (3), the shear stress of fluid hydrodynamic in both CT and conventional ST crystallizer was estimated and compared.

Meanwhile, Nguyen et al [10-15] expressed the mass transfer via the Sherwood number of fluid hydrodynamic in conventional ST crystallizer as

$$
S h=2+0.47\left(\frac{\varepsilon^{1 / 3} d_{p}^{4 / 3}}{v}\right)^{0.63} S c^{1 / 3}
$$

Thus, as using the (2) and (4), the mass transfer of fluid hydrodynamic in both CT and conventional ST crystallizer was estimated and compared.

As shown in Figure 8(a), it was revealed that the shear stress of fluid hydrodynamic in both CT and ST crystallizers increased as increasing the agitation speed of inner cylinder and impeller. However, there was a significant difference in terms of the shear stress between the CT and conventional ST crystallizer according with the agitation speed. Here, the shear stress of Taylor vortex flow in CT crystallizer was at least 23.0 times higher than that of fluid hydrodynamic in conventional ST crystallizer in a whole range of agitation speed. This result implied that the $\beta$-form nucleation was much more facilitated as using CT crystallizer compared to the conventional ST crystallizer. 


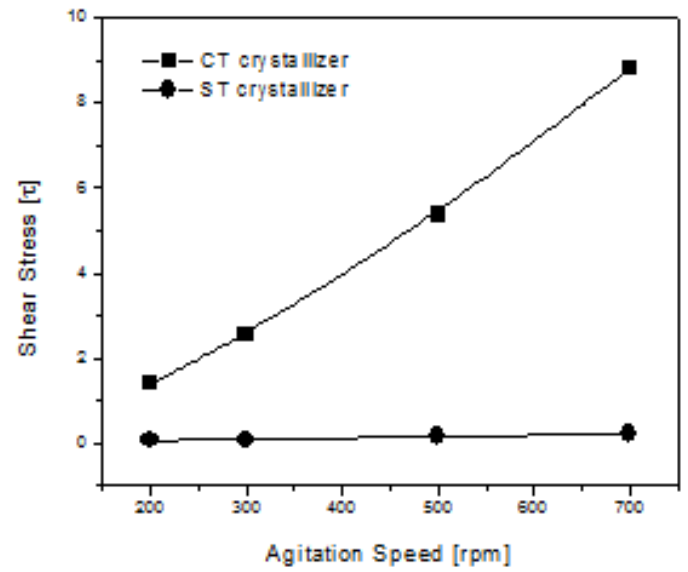

(a)

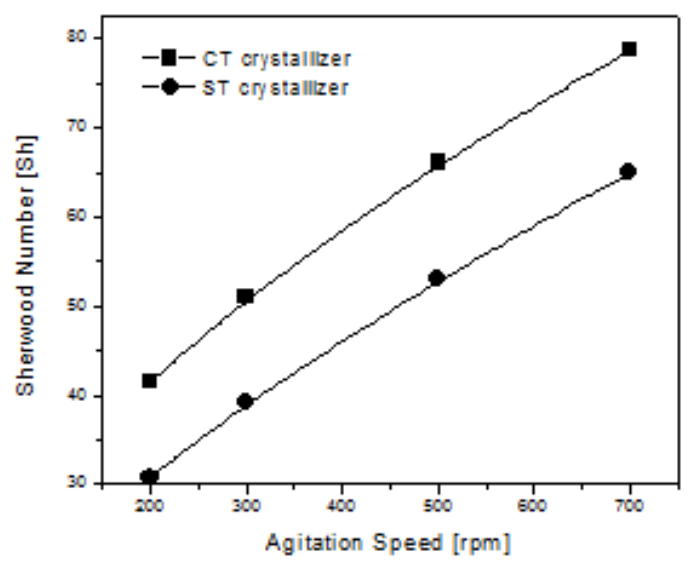

(b)

Figure 8. Comparison the shear stress and mass transfer of fluid hydrodynamic in CT and ST crystallizers

As shown in Figure 8(b), although the mass transfer of fluid hydrodynamic in both crystallizers increased as increasing agitation speed, the mass transfer of Taylor vortex flow in CT crystallizer was also at least 1.2 times higher than that of fluid hydrodynamic in conventional ST crystallizer in a wide range of agitation speed, meaning that the dissolution rate of $\alpha$ form and growth rate of $\beta$-form crystal were much more accelerated under the Taylor vortex flow in CT crystallizer compared to that under the fluid motion in conventional ST crystallizer.
Thus, the phase transformation of $\alpha$-form to $\beta$ form crystal were much more facilitated as using the CT crystallizer than that in the conventional ST crystallizer. The above result matched well with the previous result reported by Khuu et al [24], where the induction time of $\beta$-form and reconstruction time of phase transformation were significantly reduced at least 2.0 times as using the $\mathrm{CT}$ crystallizer compared to the conventional ST crystallizer.

\section{CONCLUSION}

The present study found that the intensity Taylor vortex flow in Couette-Taylor crystallizer played a key role to determine the selective polymorphism and phase transformation of L-glutamic acid in cooling crystallization. The experimental result showed that the pure $\alpha$-form crystal product was crystallized at low intensity Taylor vortex flow with moderated crystallization time as $\mathrm{t}<6$ hours, while the pure $\beta$-form crystal product was crystallized when the intensity Taylor vortex flow was large as $\mathrm{Ta}>6000$. This result indicated that it was successful to develop a proposed Couette-Taylor crystallizer in order to manufacture the pure $\alpha$-form and $\beta$-form crystal product at moderated crystallization condition at agitation speed of $300 \mathrm{rpm}$ and crystallization time of less than 6 hours. By comparison to the conventional standard stirred tank crystallizer, the Couette-Taylor crystallizer exhibited an advantage crystallizer, where the crystallization time was remarkably reduced at least 2.0 times as regards production of the pure $\beta$-form crystal products. Here, the advantage of Couette-Taylor crystallizer over the conventional stirred tank crystallizer was explained via the high shear stress and mass transfer of Taylor vortex flow in Couette-Taylor crystallizer, where the shear

\section{Trang 20}


stress and mass transfer rate of Taylor vortex flow in Couette-Taylor crystallizer were at least 23.0 times and 1.2 times higher than that of the fluid motion in the conventional stirred tank crystallizer, respectively.

\section{Nghiên cứu kết tinh dược phẩm bằng thiết bị Couette-Taylor: Kiểm soát cấu trúc tinh thể của amino acid L-glutamic acid}

- Khưu Châu Quang

- Đặng Trường Giang

- Trịnh Thị Thanh Huyền

- Nguyễn Anh Tuấn

Viện Công Nghệ Hóa Học, Viện Hàn Lâm Khoa Học Việt Nam (VAST)

\section{TÓM TĂT}

Nghiên cứu thiết kế thành công thiết bị kết tinh Couette-Taylor nhằm thúc đẩy quá trình kết tinh chọn lọc và chuyển pha giũa các cấu trúc tinh thể amino acid L-glutamic acid. Trong nghiên cứu này, sản phẩm tinh thể L-glutamic acid được chọn làm sản phẩm đặc trung cho hiện tượng đa cấu trúc vốn rất phổ biến và khó kiểm soát trong mọi quá trình kết tinh duợc phẩm. L-glutamic có hai dạng cấu trúc tinh thể gồm kém bền $\alpha$ và bền $\beta$, trong đó dạng kém bền $\alpha$ sẽ chuyển pha thành dạng bền $\beta$, và quá trình chuyển pha sẽ diễn ra trong khoảng thời gian dài trên 40 giò̀. Do vậy, để kết tinh được sản phẩm tinh thể $\beta$ với chi phí sản xuất thấp nhất đã trở thành thư thách cho mọi thiết bi kết tinh, và nghiên cứu hiện tại đã thành công khi thiết kế được thiết bi kết tinh Couette-Taylor trong việc giải quyết vấn đề khó khăn này. Kết quả nghiên cứu cho thấy, sụ chọn lọc cấu trúc dạng $\alpha$ hay $\beta$ cũng nhu quá trình chuyển pha tù $\alpha$ sang $\beta$ sẽ phu thuộc nhiều vào chế độ thủy động lục học trong thiết bi kết tinh, trong đó sụ kết tinh chọn lọc dạng cấu trúc $\beta$ và tốc độ chuyển pha tù dạng $\alpha$ sang dạng $\beta$ sẽ gia tăng nhiều lần khi sư dụng thiết bi kết tinh Couette-Taylor. Để đánh giá được giá trị của nghiên cứu, chúng tôi tiến hành nghiên cúu so sánh hai thiết bị kết tinh Couette-Taylor và thông thường khi ở cùng mọt điều kiện vận hành. Kết quả nghiên cưu so sánh cho thấy, kết tinh chọn lọc sản phẩm tinh thể $\beta$ và tốc độ chuyển pha tù dạng a sang $\beta$ được tăng lên it nhất 2.0 lần khi sủ dụng thiết bị kết 
tinh Couette-Taylor so với khi sủ dụng thiết bi kết tinh thông thuờng. Uu điểm của thiết bị kết tinh Couette-Taylor được giải thích và minh chưng thông qua ưu điểm của chế độ thủy động lục họ Taylor vortex với ứng suất cắt và độ truyền khối cao. Kết quả tính toán cho thấy, úng suất cắt của chế độ thủy động lục họ trong thiết bị kết tinh Couette-Taylor cao hơn 23 lần so với trong thiết bi kết tinh thông thuòng. Ngoài ra, độ truyền khối của chế độ thủy động lục học trong thiết bị kết tinh Couette-Taylor cũng cao hơn 1.2 lần so với trong thiết bị kết tinh thông thương. Nhu vậy, với ứng suất cao và độ truyền khối lơn, chế độ thủy động lục học Taylor vortex trong thiết bi kết tinh CouetteTaylor đã thúc đẩy sụ kết tinh chọn lọc mầm tinh thể dạng bền $\beta$, sụ hòa tan của dạng kém bền $\alpha$ và phát triển tinh thể của dạng bền $\beta$ giúp cho quá trình chuyển pha tù dạng $\alpha$ sang dạng $\beta$ nhanh hon.

Tù̀ khóa: Kết tinh, cấu trúc tinh thể, mầm tinh thể, phát triển tinh thể, tinh thể kết tụ/nứt gãy, thiết bị kết tinh Couette-Taylor.

\section{REFERENCES}

[1]. J.W Mullin, Crystallization. Oxford, 1993.

[2]. A.S Myerson, Handbook of Industrial Crystallization. Oxford, 1993.

[3]. A. Mersmann, Crystallization Technology Handbook. Marcel Dekker Inc, New York, 1995.

[4]. H.G Brittain, Polymorphism in Pharmaceutical Solids. Marcel Dekker Inc, New York, 1999.

[5]. J Bernstein, Polymorphism in Molecular Crystals. Oxford, 2002.

[6]. A.T Nguyen, K Jeongki and W.S Kim, Noncommon Ion Effect on Phase Transformation of Guanosine 5Monophosphate Disodium in Antisolvent Crystallization, Ind. Eng. Chem. Res. vol. 54, pp. 5784-5792, 2015.

[7]. K Sypek, I.S Burns, A.J Florence and J Sefcik, In Situ Monitoring of Stirring Effects on Polymorphic Transformations during Cooling Crystallization of
Carbamazepine, Cryst. Growth. Des. vol. 12, pp. 4821-4828, 2012.

[8]. R Davey, N Blagden, S Righini, H Alison and E Ferrari, Nucleation control in solution mediated polymorphic phase transformations: the case of 2, 6dihydroxybenzoic acid, J. Phys. Chem. B. vol. 106, pp. 1954-1959, 2002.

[9]. S Maruyama, H Ooshima and J Kato, Crystal structures and solvent-mediated transformation of taltireline polymorphs, Chem. Eng. J. vol. 75, pp. 193-200, 1999.

[10].A.T Nguyen, J.M Kim, S.M Chang and W.S Kim, Taylor vortex effect on phase transformation of guanosine 5monophosphate in drowning-out crystallization, Ind. Eng. Chem. Res. vol. 49, pp. 4865-4872, 2010.

[11].A.T Nguyen, J.M Kim, S.M Chang and W.S Kim, Phase Transformation of Guanosine 5-Monophosphate in Continuous Couette-Taylor Crystallizer: Experiments and Numerical Modeling for 
Kinetics, Ind. Eng. Chem. Res. vol. 50, pp. 3483-3493, 2011.

[12].A.T Nguyen, K Jeongki, G.J Choi and W.S Kim, Phase transformation of guanosine 5'-monophosphate in drowning-out crystallization: Comparison of experimental results with mathematical modeling, Cryst. Res. Technol. vol. 46, pp. 53-60, 2011.

[13].A.T Nguyen, Y.L Joo and W.S Kim, Multiple Feeding Strategy for Phase Transformation of GMP in Continuous Couette-Taylor Crystallizer, Cryst. Growth. Des. vol. 12, pp. 2780-2788, 2012.

[14].A.T Nguyen, K Jeongki and W.S Kim, Influence of salt additives on phase transformation of guanosine 5monophosphate disodium in anti-solvent crystallization, J. Cryst. Growth. vol. 373, pp. 82-87, 2013.

[15].A.T Nguyen, $\mathrm{T} \mathrm{Yu}$ and W.S Kim, Development of Couette-Taylor Crystallizer: Promotion of Size Distribution and Recovery of L-lysine in Cooling Crystallization. J. Cryst. Growth. Submitted (2016).

[16].S Lee, A Choi, W.S Kim and A.S Myerson, Phase transformation of sulfamerazine using a Taylor Vortex, Cryst. Growth. Des. vol. 11, pp. 5019-5029, 2011.

[17].M Kitamura, Polymorphism in the crystallization of L-glutamic acid, J. Cryst. Growth. vol. 96, pp. 541-546, 1989.

[18].A.J Florence, N.E.B Briggs, U Schacht, V Raval, $\mathrm{T}$ McGlone and $\mathrm{T}$ Sefcik, The seeded crystallization of $\beta$ L-glutamic acid in a continuous oscillatory baffled crystallizer, J. Org. Process. Res. Dev. vol. 19, pp. 1903-1911, 2015.

[19].K Biradha, China-India-Singapore Expanded to South and East Asia. Cryst. Growth. Des. vol 15, pp. 1-1, 2015.

[20].K Biradha, C.Y Su and J.J Vittal, Recent Developments in Crystal Engineering, Cryst. Growth. Des. vol. 11, pp. 875-886, 2011.

[21].K.T.P Nguyen, C.Q Khuu, D.T Nguyen, T.D.T Tran, T.T.H Trinh, T.T.H Le, V.D Trinh, T.H.N Le, T.K.D Hoang, T.T Phan and A.T Nguyen, Polymorphism of $L$ glutamic Acid: Influence of the Additive Ammonium Sulphate upon the Phase Change between $\alpha$ - and $\beta$-polymorphs, Malay. J. Chem. vol. 17, pp. 38-46, 2015.

[22].A.S Myerson and B.L Trout, Nucleation from solution, Science. vol. 341, pp. 855, 2013.

[23].L.M Warren, C.S Julian and H Peter, Unit Operations of Chemical Engineering $6^{\text {th }}$. McGraw Hill, Boston, 2001.

[24].C.Q Khuu, T.G Dang, D.T Nguyen, T.H.N Le, T.T Phan, T.T.H Trinh and A.T Nguyen, Crystallization in Couette-Taylor Crystallizer: Effect of Taylor Vortices Flow on the Nucleation and Reconstruction of $L$ Glutamic Acid in Cooling Crystallization, Journal of Science and Technology. In Press, 2016. 